\section{Bei Personalsuche nicht in Diskriminierungsfalle tappen}

Früher war die Mitarbeitersuche einfach: Man gab eine Stellenanzeige auf und suchte sich den Bewerber aus, der am besten gefiel und ins Praxisteam passte. Seit 2006 das Allgemeine Gleichbehandlungsgesetz (AGG) in Kraft ge-

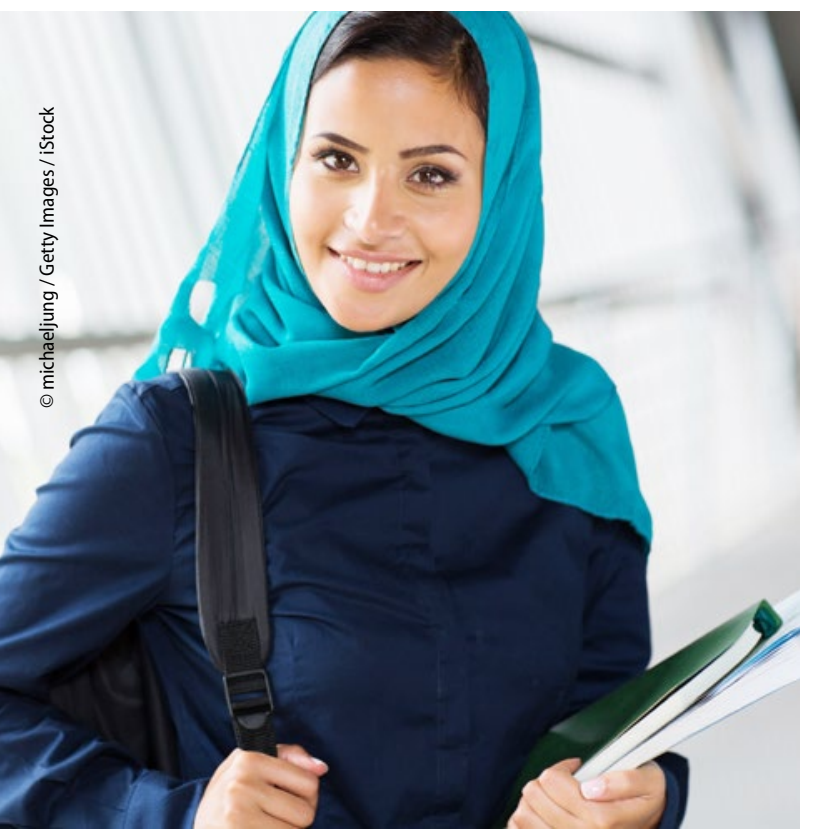

Zu weiblich? Zu jung? Zu verhüllt? Das dürfen alles keine Ablehnungsgründe sein! treten ist, muss man sich jedes Wort in der Stellenausschreibung genau überlegen. Denn wer sich auch nur dem Verdacht aussetzt, einen Bewerber aus diskriminierenden Gründen abgelehnt zu haben, muss mit finanziellen Konsequenzen rechnen. Bis zu drei Monatsgehälter können ausgemusterte Kandidaten fordern.

\section{MMW-KOMMENTAR}

Eine Ablehnung darf auf keinen Fall mit der Rasse oder der ethnischen Herkunft, dem Geschlecht, der Religion oder der Weltanschauung, einer möglichen Behinderung, dem Alter oder der sexuellen Identität eines Kandidaten begründet werden. Männer und Frauen, Homosexuelle und Heteros, Atheisten und Religiöse aller Arten, Alte und Junge, Deutsche und Ausländer sollen am Arbeitsmarkt dieselben Chancen haben.

In den vergangenen Jahren haben Gerichte die Vorgaben des Gesetzes für die Praxis konkretisiert. So ist z. B. nach einem Urteil des Landesarbeitsgerichts Düsseldorf bereits die Formulierung "Berufseinsteiger" in einer

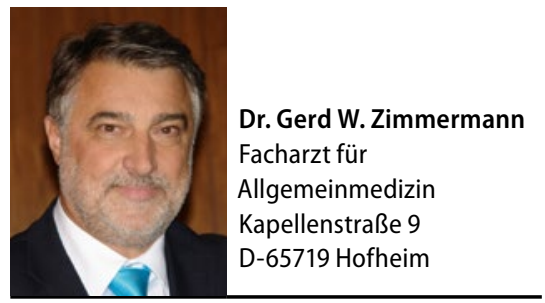

Stellenanzeige diskriminierend, weil sie Bewerber höheren Alters von vornherein ausschließt (Az.: 13 Sa 1198/13).

Auch bei der eigentlichen Entscheidung für einen Bewerber kann man sich angreifbar machen. So musste ein Zahnarzt drei Monatsgehälter Schadensersatz an eine muslimische Bewerberin zahlen, die er als Auszubildende abgelehnt hatte, weil sie in der Praxis ihr Kopftuch nicht ablegen wollte. Dies aber wertete das Arbeitsgericht Berlin als unmittelbare Ausübung der Religion (Az.: 55 C1 2426/12).

Eine Stellenausschreibung sollte deshalb auf das Wesentliche beschränkt sein, etwa die gewünschte Qualifikation (Ausbildung, Zusatzqualifikationen, Sprachkenntnisse, EDVKenntnisse etc.) und erforderliche Talente (Kommunikationsvermögen, Teamfähigkeit etc.). Auch ist es wichtig, durchgängig geschlechtsneutrale Bezeichnungen zu verwenden. Selbst Formulierungen wie „zur Verstärkung unseres jungen Teams" können bereits Anlass für Diskriminierungsklagen sein. Auch Vorgaben wie "Muttersprache deutsch" oder "deutsche Staatsangehörigkeit" sollten vermieden werden. Verlangen kann man hingegen „perfekte Kenntnisse der deutschen Sprache".

\title{
Nur eine neue Praxis ist eine „Jungpraxis"
}

— Was ist eigentlich eine „Jungpraxis“? Der Rechtsbegriff ist vage, und somit ist auch nicht völlig klar, welche Praxen bei der Bemessung des Regelleistungsvolumens (RLV) von den Regelungen für sogenannte Anfängerpraxen profitieren. Eine Ärztin aus Bayern wollte es nun genau wissen: Nach der Auflösung einer Berufsausübungsgemeinschaft (BAG) hatte sie sich mit z.T. neuen Partnern eigenständig niedergelassen - und vor Gericht auf die Zuteilung eines gesonderten RLV geklagt. Das Landessozialgericht (LSG) Bayern entschied aber, dass nur Erstzulassungen oder Neuzulassungen in einem anderen Planungsbereich eine Einordnung als Jungpraxis begründen (Az.: L 12 KA 64/14).

\section{MMW-KOMMENTAR}

Das Bundessozialgericht (BSG) hatte 2013 die Situation nach dem Ausscheiden aus einer BAG noch offen gelassen (Az: B 6 KA 44/12 R). Das $L S G$ hat nun für diese Fälle die Anfängerregelung verweigert. Die Richter sahen die Gefahr, dass Ärzte die RLV-Fallzahlbegrenzungen durch zivilrechtliche Vertragsgestaltungen unterlaufen könnten. 